\title{
Aplicação de IP na localização de zona mineralizada em sulfeto disseminado, Ourilândia do Norte/PA
}

João Fernando Pezza Andrade (jfernando.geof@gmail.com) - PHYGEO / UnB

Fábio Augusto dos Santos Rocha (fabio.fasr@gmail.com) - PHYGEO / UnB

Amanda Almeida Rocha (amanda7k@gmail.com) - PHYGEO / UnB

Welitom Rodrigues Borges (welitom@unb.br) - Instituto de Geociências / UnB

Jadson Muniz de Oliveira (jadsonjmo@gmail.com) - PHYGEO / UnB

Copyright 2014, SBGf - Sociedade Brasileira de Geofísica

Este texto foi preparado para a apresentação no VI Simpósio Brasileiro de Geofísica, Porto Alegre, 14 a 16 de outubro de 2014. Seu conteúdo foi revisado pelo Comité Técnico do VI SimBGt, mas não necessariamente representa a opinião da SBGf ou de seus associados. É proibida a reprodução total ou parcial deste material para propósitos comerciais sem prévia autorização da SBGf.

\section{Abstract}

This work presents the results of induced polarization obtained at the region of Ourilândia do Norte, PA. The 2D investigations of IP aimed to locate a disseminated copper sulfide deposit at the northwest of Sector Rio Maria, in the Carajás Mineral Province. In the aquisition of data, dipole-dipole and pole-dipole arrays were used, both with a spacing of 10 meters between the electrodes and with 10 levels of depth. The chargeability results made possible to delineate the mineralized zone located at the investigated area, which will direct the copper extraction.

\section{Introdução}

A Província Carajás, segmento mais antigo do Cráton Amazônico (Tassinari e Macambira, 2004), é uma região muito explorada com ampla riqueza mineral. A Província Carajás é subdividida nos domínios Rio Maria e Carajás (Vasquez et al., 2008). O escopo do projeto foi localizar e caracterizar depósitos de sulfeto de cobre disseminado na região de Ourilândia do Norte, PA. De acordo com o mapa geológico do estado do Pará (Escala 1:1000000, CPRM, 2008), ocorre na área o Granodiorito Rio Maria (GDrm). Informações prévias proporcionaram indicações da posição e da direção do corpo anômalo, onde se aplicou o método da polarização induzida com o intuito de definir o local, os limites, e o potencial de exploração do deposito.

\section{Metodologia}

O método de polarização induzida é extensivamente utilizado na exploração de metais básicos, o fenômeno de IP mostra-se eficiente na localização dos depósitos de minério de baixo teor (Kearey 2006). O prévio conhecimento da geologia local e das características do alvo fizeram da técnica de polarização induzida a melhor escolha para a caracterização da zona mineralizada.

A polarização induzida é um fenômeno físico elétrico, estimulado pela transmissão de uma corrente elétrica pulsante e periódica no subsolo, observada como uma resposta defasada de voltagem nos materiais terrestres (Sumner et al., 1976; Moura et al., 2002) a qual se relaciona com a cargabilidade dos materiais em subsuperfície. A resposta da polarização induzida é uma quantidade, com dimensões muito reduzidas, sendo na pratica medida tal como uma variação de voltagem em função do tempo ou frequência (Braga et al., 2007). O levantamento realizado neste trabalho foi feito no domínio do tempo, no qual se faz medições do decaimento de voltagem em um certo período de tempo.

O levantamento realizado constituiu na aquisição, processamento e interpretação de 5 perfis, utilizando a técnica do caminhamento elétrico, que totalizaram 780 metros (Figura 1), todas as linhas foram adquiridas na direção sul para norte.

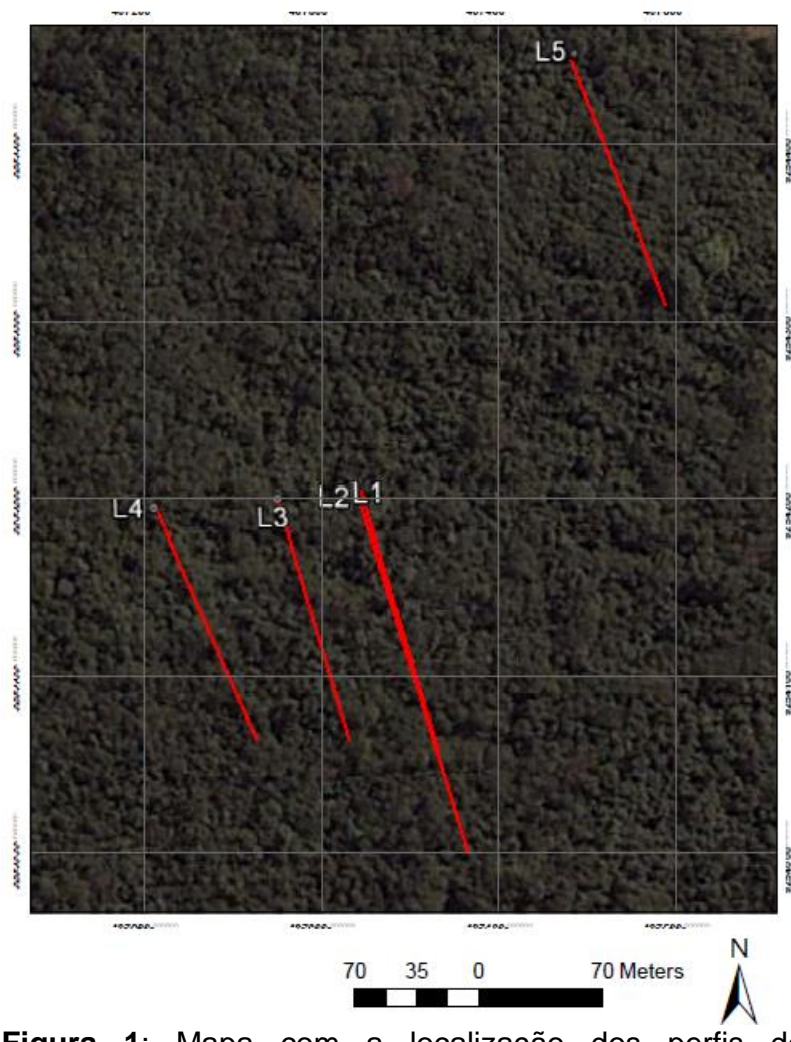

Figura 1: Mapa com a localização dos perfis de caminhamento elétrico de IP. 
$\mathrm{Na}$ aquisição usou-se o equipamento Syscal Pro, calibrado de acordo com ciclos periódicos de corrente alternada, com injeção de $800 \mathrm{~V}$ de corrente, em ciclos de 2 segundos. As linhas foram adquiridas com espaçamento entre os eletrodos de $10 \mathrm{~m}$ utilizando 11 eletrodos porosos com um total de 10 níveis de investigação e georreferenciadas com um GPS.

Após a aquisição de dados, usou-se o software Prosys para a realização de uma filtragem manual, o que removeu os dados incoerentes (spikes). A modelagem por mínimos quadrados foi realizada no software Res2dinv.

\section{Resultados}

Os resultados da modelagem (Figura 2) evidenciam uma variação de cargabilidade de 5 a $80 \mathrm{mV} / \mathrm{V}$. Os valores de cargabilidade para o background ficaram abaixo de 25 $\mathrm{mV} / \mathrm{V}$, e para a possível zona mineralizada os valores de cargabilidade ficaram acima de $30 \mathrm{mV} / \mathrm{V}$.

Na linha 1 (Figura 2) nota-se um corpo anômalo de alta cargabilidade na região sul da linha, a qual é relacionada com a zona mineralizada. A linha 2 (L2), devido a sua maior extensão e por ter um melhor posicionamento sobre o alvo, foi a que melhor representou a zona mineralizada. Observa-se a anomalia no centro do perfil (Figura 2), com profundidade aproximada de 25 metros, e largura de 50 metros. A inversão cria um efeito de borda, dando uma falsa impressão de mapeamento da base do corpo.
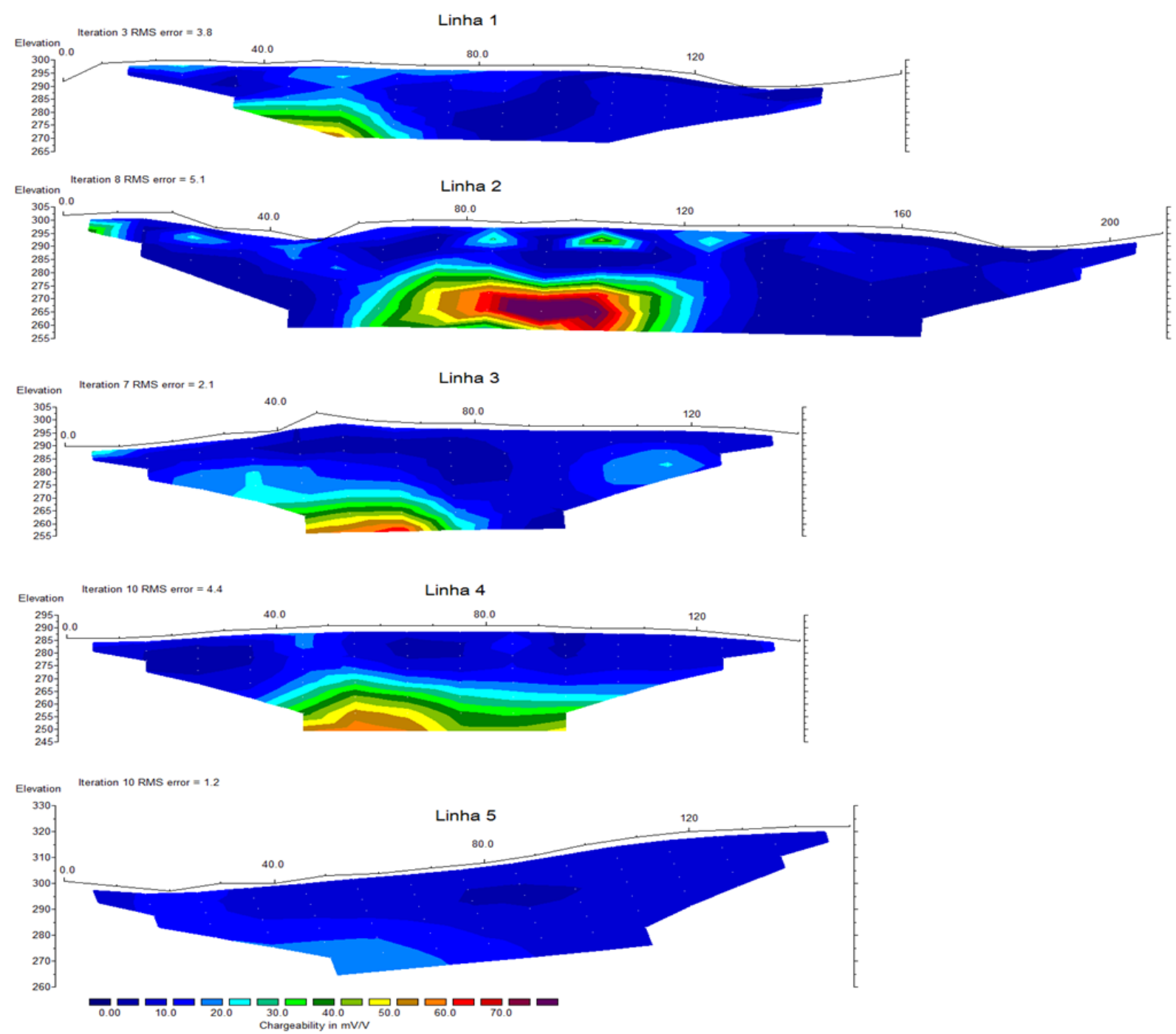

Figura 2: Seções de cargabilidade das linhas L1, L2, L3, L4 e L5 obtidas após a modelagem inversa desenvolvida no software Res2dinv. 
A terceira linha de aquisição (L3) mostrou uma anomalia na parte mais ao sul, também com profundidade aproximada de 25 metros, o que indica a continuação do corpo (Figura 2). Devido a anomalia estar no limite da linha se supõe que ela tenha continuidade a sul, fora da propriedade do cliente. $\mathrm{Na}$ última linha paralela, L4, também se observa uma região anômala, porém mais ampla e com maior profundidade (Figura 2).

Os dados indicam que o corpo tem direção WNW com indícios de que o minério tem continuidade tanto a oeste quanto a leste. Com a análise dos dados altimétricos no topo da anomalia nas linhas 2, 3 e 4, é assumido que o sulfeto tem mergulho para WNW (Figura 3).

A linha 5, feita ao norte das linhas paralelas (Figura 2), não mostrou padrões anômalos, o que sugere que não há minério ou que o corpo mineralizado se encontra em maiores profundidades.

\section{Discussão e conclusão}

Conhecidos os resultados dos dados geofísicos, aliados ao conhecimento geológico da área, foi possível caracterizar o deposito e definir o seu potencial de exploração mineral. As linhas paralelas, em sua totalidade, apresentaram resultados indicando a zona mineralizada. As aquisições de mais linhas na área poderiam proporcionar um maior conhecimento do corpo mineralizado, porém em virtude do orçamento e do contratante não se realizaram outras seções de IP paralelas, mas sim uma outra linha na região alvo mais a norte.

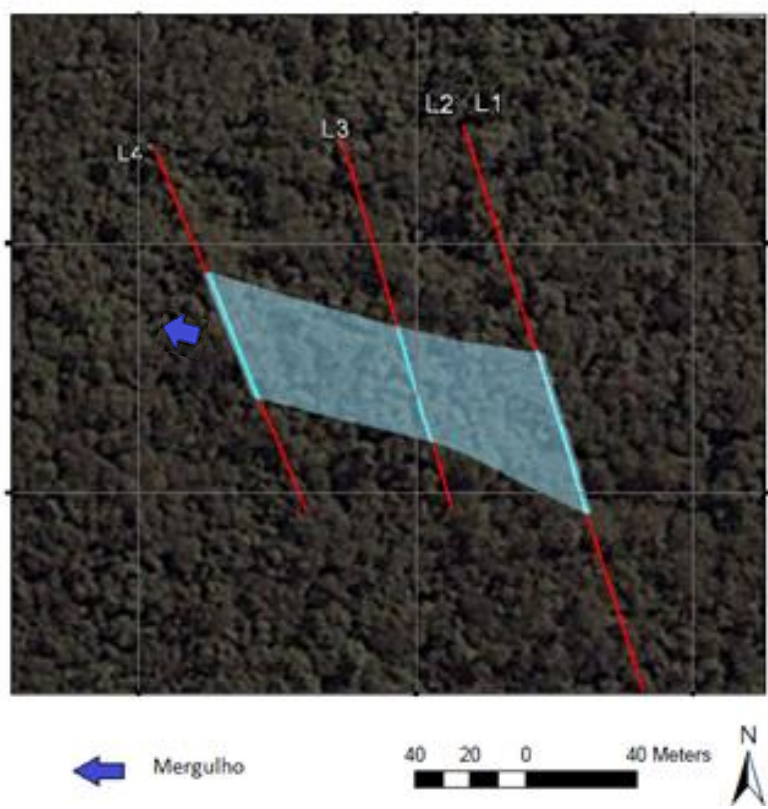

Figura 3: Projeção da zona mineralizada identificada nas seções de cargabilidade desenvolvidas na área.

\section{Agradecimentos}

Ao Laboratório de Geofísica Aplicada (LGA/IG/UnB) pela disponibilização dos equipamentos geofísicos.

A Empresa Guimalhães por autorizar o uso dos dados para publicação do trabalho realizado.

\section{Referências}

Braga, ACO. 2007. Módulo: Métodos Geoelétricos Aplicados nos Estudos de Captação e Contaminação das Águas Subterrrâneas. Instituto de Geociências e Ciências Exatas - IGCE. Departamento de Geologia Aplicada DGA. Universidade Estadual Paulista "Julio de Mesquita Filho". UNESP, Rio Claro 2007.

Kearey, P; Broocks, M; Hill, I. 2006. An Introduction to Geophysical Exploration. 3 $3^{\underline{a}}$ nd. Edition, Blackwell Publishing. 2006, 262 p.

Moura, HP. 2002. Emprego da eletrorresistividade e da polarização induzida na caracterização geoelétrica de áreas de disposição de resíduos sólidos urbanos. Rio Claro, Tese (Doutorado em Geociências e Meio Ambiente) - Instituto de Geociências e Ciências Exatas, Universidade Estadual Paulista, 231p.

Sumner, JS. 1976. Principles of induced polarization for geophysical exploration. New York: Elsevier Scientific Publishing Company, $277 \mathrm{p}$.

Tassinari, CCG; Macambira, M. 2004. A evolução tectônica do Craton Amazônico. In: Mantesso-Neto, V; Bartorelli, A; Carneiro, CDR; Brito Neves, BB. (Eds.), Geologia do Continente Sul Americano: Evolução da obra de Fernando Flávio Marques Almeida. São Paulo, pp. 471-486.

White, SRMS; Collins, R; Denne, R; Hee, R; BROWN, P. 2001. A new survey design for $3 D$ IP inversion modelling at Copper Hill. Exploration Geophysics, v. 32, p. 152-155.

Vasquez, LV; Rosa-Costa, LR; Silva, CG; Ricci, PF; Barbosa, JO; Klein, EL; Lopes, ES; Macambira, EB; Chaves, CL; Carvalho, JM; Oliveira, JG; Anjos, GC; Silva, HR. 2008. Geologia e Recursos Minerais do Estado do Pará: Sistema de Informações Geográficas-SIG: texto explicativo dos mapas Geológico e Tectônico e de Recursos Minerais do Estado do Pará, 328p

Vasquez, ML; Sousa, CS; Carvalho, JMA. (Orgs.). 2008. Mapa Geológico e de Recursos Minerais do Estado do Pará, escala 1:1.000.000. Programa Geologia do Brasil (PGB), Integração, Atualização e Difusão de Dados da Geologia do Brasil, Mapas Geológicos Estaduais. CPRMServiço Geológico do Brasil, Superintendência Regional de Belém. 